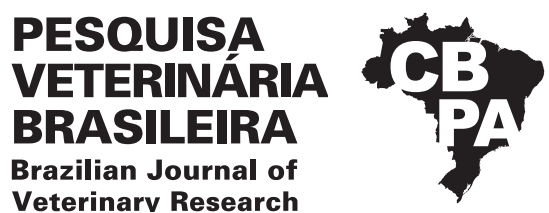

Pesq. Vet. Bras. 41:e06810, 2021

DOI: $10.1590 / 1678-5150-P V B-6810$

Original Article

Small Animal Diseases

ISSN 0100-736X (Print)

ISSN 1678-5150 (Online)

\title{
Echocardiographic features of pre- and postcapillary pulmonary hypertension with a focus on the right ventricle in $\operatorname{dog} s^{1}$
}

\author{
Jaislane B. Braz ${ }^{2 *}$ (D), Aparecido Antonio Camacho ${ }^{2}$, Raphaela A.M. Canola², \\ Tamyris Beluque $^{2}$ (D) Evandro Zacché2 ${ }^{2}$ Jorge C. Silva-Filho², Wilmer A. Zamora ${ }^{2}$ \\ and Marlos G. Sousa ${ }^{3}$
}

\begin{abstract}
Braz J.B., Camacho A.A., Canola R.A.M., Beluque T., Zacché E., Silva-Filho J.C., Zamora W.A. \& Sousa M.G. 2021. Echocardiographic features of pre- and postcapillary pulmonary hypertension with a focus on the right ventricle in dogs. Pesquisa Veterinária Brasileira 41:e06810, 2021. Departamento de Medicina Veterinária e Cirurgia, Escola de Agronomia e Ciências Veterinárias, Universidade Estadual de São Paulo "Júlio de Mesquita Filho", Via de Acesso Prof. Paulo Donato Castellane s/n, Jaboticabal, SP 14884-900, Brazil. E-mail: jaislanemedvet@gmail.com

Pulmonary hypertension (PH) in dogs is a syndrome that can occur secondary to several causes, including left heart disease (postcapillary) and chronic respiratory disease (precapillary). This study evaluates morphological and functional consequences in the right ventricle (RV) of dogs with pre- and postcapillary PH through echocardiography, and also considers the severity of PH (mild, moderate or severe). Echocardiography was performed on 66 dogs of various breeds and weights (age $>3$ years old) which were assigned to three groups: postcapillary $\mathrm{PH}$, which included mitral valve disease/endocardiosis, precapillary $\mathrm{PH}$, which included chronic respiratory diseases (bronchitis, collapse of the trachea and primary lung cancer or metastasis), and finally, a healthy group of controls. The parameters for RV morphology were RV1, RV2, and RV3 for systole and diastole. The following measurements were used to assess RV systolic function: tricuspid annular plane systolic excursion (TAPSE), TAPSE:Ao (aorta), maximum velocity of the tricuspid systolic wave obtained by tissue Doppler ( $\left.S^{\prime}\right), S^{\prime}$ :Ao, right ventricle end-diastolic area (RVEDA); RVEDA:BSA (body surface area); flow velocity integral (FVI) and FVI:Ao. The variables were assessed using ANOVA. The results showed that RV3d, RV1s, S':Ao, S', and FVI were able to distinguish cases of pre- and postcapillary PH in this study. Remodeling of the RV of dogs with $\mathrm{PH}$ was observed, which can be influenced by the pre- or postcapillary origin of the $\mathrm{PH}$, with dilation in dogs with postcapillary $\mathrm{PH}$ and severe $\mathrm{PH}$. The results for RV systolic function were similar, with FVI and FVI:Ao showing that RV ejection function is reduced in dogs with postcapillary PH and with severe PH.
\end{abstract}

INDEX TERMS: Echocardiography, precapillary, postcapillary, pulmonary hypertension, right ventricle, dogs, cardiovascular diseases, endocardiosis, small animal medicine, cardiology.

RESUMO.- [Características ecocardiográficas da hipertensão pulmonar pré e pós-capilar em cães com foco no ventrículo direito.] A hipertensão pulmonar (HP) em cães é uma síndrome

\footnotetext{
${ }^{1}$ Received on February 2, 2021.

Accepted for publication on March 3, 2021.

${ }^{2}$ Departamento de Medicina Veterinária e Cirurgia, Escola de Agronomia e Ciências Veterinárias, Universidade Estadual de São Paulo "Júlio de Mesquita Filho" (Unesp), Via de Acesso Prof. Paulo Donato Castellane s/n, Jaboticabal, SP 14884-900, Brazil. *Corresponding author: jaislanemedvet@gmail.com

${ }^{3}$ Departamento de Medicina Veterinária, Universidade Federal do Paraná (UFPR), Rua dos Funcionários 1540, Cabral, Curitiba, PR 80035-050, Brazil.
}

que pode ocorrer secundária às diversas causas, dentre elas, a doença cardíaca esquerda (pós-capilar) e a doença respiratória crônica (pré-capilar). Essa é uma condição importante que motivou os objetivos do estudo: avaliar ecocardiograficamente as consequências morfológicas e funcionais no ventrículo direito (VD) dos cães acometidos com HP pré- e pós-capilar, considerando também o estágio de severidade da HP (leve, moderada ou severa). A ecocardiografia foi realizada em 66 cães de diversas raças e pesos, com pelo menos quatro anos de idade, que compuseram um grupo com doença valvar mitral, ou endocardiose, outro com doença respiratória 
crônica (bronquite, colapso de traqueia e neoplasia pulmonar primária ou metástase), e por último, um grupo saudável. Os parâmetros para a morfologia do VD foram RV1, RV2 e RV3 na sístole e na diástole. Para a avaliação da função sistólica do VD foram mensurados: excursão sistólica do plano anular tricúspide (TAPSE), TAPSE:Ao (aorta), velocidade máxima da onda sistólica da tricúspide obtida pelo doppler tecidual $\left(S^{\prime}\right)$, $S^{\prime}:$ Ao, área do ventrículo direito no final da diástole (RVEDA); RVEDA:BSA (body superficie area); integral tempo velocidade (FVI) e FVI:Ao. As variáveis foram avaliadas por meio da ANOVA. Os resultados mostraram que RV3d, RV1s, S':Ao, S' e FVI foram capazes de distinguir casos de HP pré e pós-capilar neste estudo. Observou-se que há remodelamento do VD de cães com HP e este pode ser influenciado pela origem pré ou pós-capilar da HP, encontrando-se dilatado em cães com HP pós capilar e com HP severa. Os resultados para a função sistólica do VD foram similares, uma vez que o FVI e FVI:Ao mostraram que a capacidade de ejeção do VD está reduzida nos cães com HP pós-capilar e com HP severa.

TERMOS DE INDEXAÇÃO: Ecocardiografia, hipertensão pulmonar, pré-capilar, pós-capilar, cães, ventrículo direito, caninos, doença cardiovascular, endocardiose, medicina de pequenos animais, cardiologia.

\section{INTRODUCTION}

Pulmonary hypertension $(\mathrm{PH})$ is defined as pulmonary artery systolic pressure greater than $30 \mathrm{mmHg}$ for the canine species (Kellihan et al. 2015). In dogs, precapillary PH originates in the pulmonary arterial vasculature secondary to hypoxia, chronic respiratory diseases, thromboembolism, and lung neoplasia; postcapillary $\mathrm{PH}$, in turn, originates from the pulmonary venous vasculature, as a consequence of left-sided heart disease (Kellihan \& Stepien 2012). Both forms cause pressure overload and changes to the right ventricle (RV), but the triggers are different in precapillary and postcapillary $\mathrm{PH}$ (Szabó et al. 2006, Freed et al. 2016). Pulmonary hypertension is usually diagnosed with an echocardiograph (a non-invasive and easily reproducible technique), where the velocity of tricuspid reflux can be estimated and inserted into the modified Bernoulli equation (Kellihan \& Stepien 2010).

Since the RV was first identified as an important marker for global cardiac function, many studies have investigated its morphology and function; because of its distinct characteristics in comparison to the left ventricle, however, echocardiographic evaluation of this structure must be standardized in animals (as it has been in humans) (Rudski et al. 2010, Visser et al. 2014, Gentile-Solomon \& Abbott 2016). Parameters that are easy to obtain and highly reproducible, such as tricuspid annular plane systolic excursion (TAPSE) and maximal annulus tricuspid systolic velocity ( $\left.\mathrm{S}^{\prime}\right)$, can be used to evaluate RV function (Visser et al. 2014, 2015, Chetboul et al. 2016). A low TAPSE value has been associated with poor prognosis in human patients with right heart failure secondary to $\mathrm{PH}$ (Fields et al. 2011).

In veterinary medicine, more detailed assessment of the RV has recently been included in the echocardiographic examination, in healthy dogs (to obtain reference values) as well as those with $\mathrm{PH}$ in order to investigate RV impairment (Paige \& Abbott 2007, Gentile-Solomon \& Abbott 2016). This RV assessment may predict the development of right congestive heart failure in patients with $\mathrm{PH}$, and also help establish a prognosis for this condition (Vonk Noorddegraaf et al. 2017). In dogs with PH secondary to heart disease or respiratory diseases, Pariaut et al (2012) has shown TAPSE to also be very reliable in assessing impairment of systolic function.

Furthermore, right and left ventricular interdependence can suggest global cardiac impairment due to the effect of PH on the RV (Greyson 2010). This study was designed to investigate changes in RV morphology and function in dogs with either pre- or postcapillary pulmonary hypertension, and also to evaluate the severity of remodeling and functional impairment of the right ventricular chamber according to the severity of PH.

\section{MATERIALS AND METHODS}

This prospective cross-sectional study was undertaken from 2015 to 2017, and approved by the institutional review board (process 12080/15). We selected dogs with a diagnosis of PH determined from transthoracic echocardiography.

Inclusion criteria were age $>3$ years old, weight $\leq 25 \mathrm{~kg}$, and tricuspid regurgitation velocity $\geq 2.8 \mathrm{~m} / \mathrm{s}$. Dogs with chronic obstructive pulmonary disease such as tracheal collapse, chronic bronchitis, or primary or secondary lung neoplasms were included in the precapillary PH group. The postcapillary PH group was comprised of dogs with myxomatous mitral valve disease (MMVD) (endocardiosis) and left atrial aortic ratio (LA:Ao) $\geq 1.6$. Exclusion criteria were identification of anemia, intrathoracic mass that made it impossible to obtain echocardiographic images, or clinical instability due to non-cardiac conditions other than respiratory disease. Clinically unstable dogs were stabilized for cardiac exams and consequently distributed into the respective groups.

The dogs were then allocated into groups according to the severity of PH: mild (tricuspid regurgitation velocity $\geq 2.8<3.5 \mathrm{~m} / \mathrm{s}$ ), moderate (TR velocity 3.5 to $4.3 \mathrm{~m} / \mathrm{s}$ ), or severe (TR velocity $>4.3 \mathrm{~m} / \mathrm{s}$ ) (Kellihan \& Stepien 2010). The dogs in the precapillary PH group were diagnosed with bronchitis, tracheal collapse, brachycephalic syndrome, pneumonia, bronchogenic carcinoma, pulmonary metastasis, or obesity. However, some animals also had B1 stage MMVD (without cardiac remodeling or venous congestion). The dogs in the PH postcapillary group had MMVD with signs of venous congestion assessed by echocardiography or radiography. In addition to the diseased dogs, sixteen healthy dogs were also enrolled to form the control group. The animals were selected from the clinical practice of the "Cardiologia Veterinária" and "Clínica Médica de Pequenos Animais" services, "Hospital Veterinário" of "Universidade Estadual Paulista" (Jaboticabal campus), and additional control animals were recruited from breeding dogs in the "Laboratório de Pesquisa em Nutrição e Doenças Nutricionais de Cães e Gatos Prof. Dr. Flávio Prada" at the same institution.

Echocardiography. Transthoracic echocardiography was performed on conscious patients, initially using the left parasternal window. The images of the RV were obtained by slight modification of the standard images to optimize views of the right ventricular chamber. Morphology and systolic function were evaluated according to Rudski et al. (2010). The images are presented in Figure 1-6. The following views were obtained: 1) RV internal diameter, extending from its free wall to the interventricular septum at the base (RV1) and in the papillary plane (RV2) of the RV, in diastole and systole; 2) RV length, extending from the right ventricular apex to the tricuspid annular plane, in diastole and systole. 
To evaluate RV systolic function, the following parameters were measured: 1) TAPSE, representing the longitudinal displacement of the tricuspid plane in M-mode images, with the cursor positioned over the lateral tricuspid annulus; 2) Velocity of longitudinal myocardial motion at the lateral tricuspid annulus ( $\left.\mathrm{S}^{\prime}\right)$, obtained by pulsed-wave tissue Doppler imaging (TDI), with the cursor positioned over the lateral tricuspid annulus; 3) Flow velocity integral obtained from the pulmonary artery $\left(\mathrm{FVI}_{\text {Pulm }}\right)$, determined from the contour of the spectral envelope of the pulmonary flow; 4) Right ventricle enddiastole area (RVEDA), obtained by delimiting the lateral tricuspid to the septal annulus, being careful not to include the area of the annulus and trabecular structures related to the RV endocardium.

Parameters already known to be influenced by body weight, namely TAPSE (Caivano et al. 2018) and S' (Visser et al. 2014), were indexed by aortic diameter, obtained from transverse images in the aortic plane. RVEDA was indexed by body surface area (BSA)
(Grünig et al. 2015, Lang et al. 2015) using the following formula: $0.101 \times$ body weight $(\mathrm{kg}) 2 / 3$ (Chun et al. 2007).

Statistical analysis. The data were tabulated according to group distribution. Demographic and PH severity data were subjected to the Shapiro-Wilk normality test. For normally distributed data, means and standard deviations were calculated and ANOVA was used for comparison between groups; where differences occurred, the Tukey test was used for multiple comparison of the means. Medians and interquartile ranges were calculated for the non-parametric data with the Kruskal-Wallis Test, followed by the Dunn test for inter-group comparison. Statistical analyses were considered significant at $p<0.05$.

After application of the Shapiro-Wilk test, the control group (dogs without PH) was compared with the PH group using Student's t-test for parametric data; when the data were non-parametric, the Mann-Whitney rank sum test was applied. Statistical analysis was considered significant at $p<0.05$. Finally, the precapillary and postcapillary groups were analyzed with the Cramer-von Mises
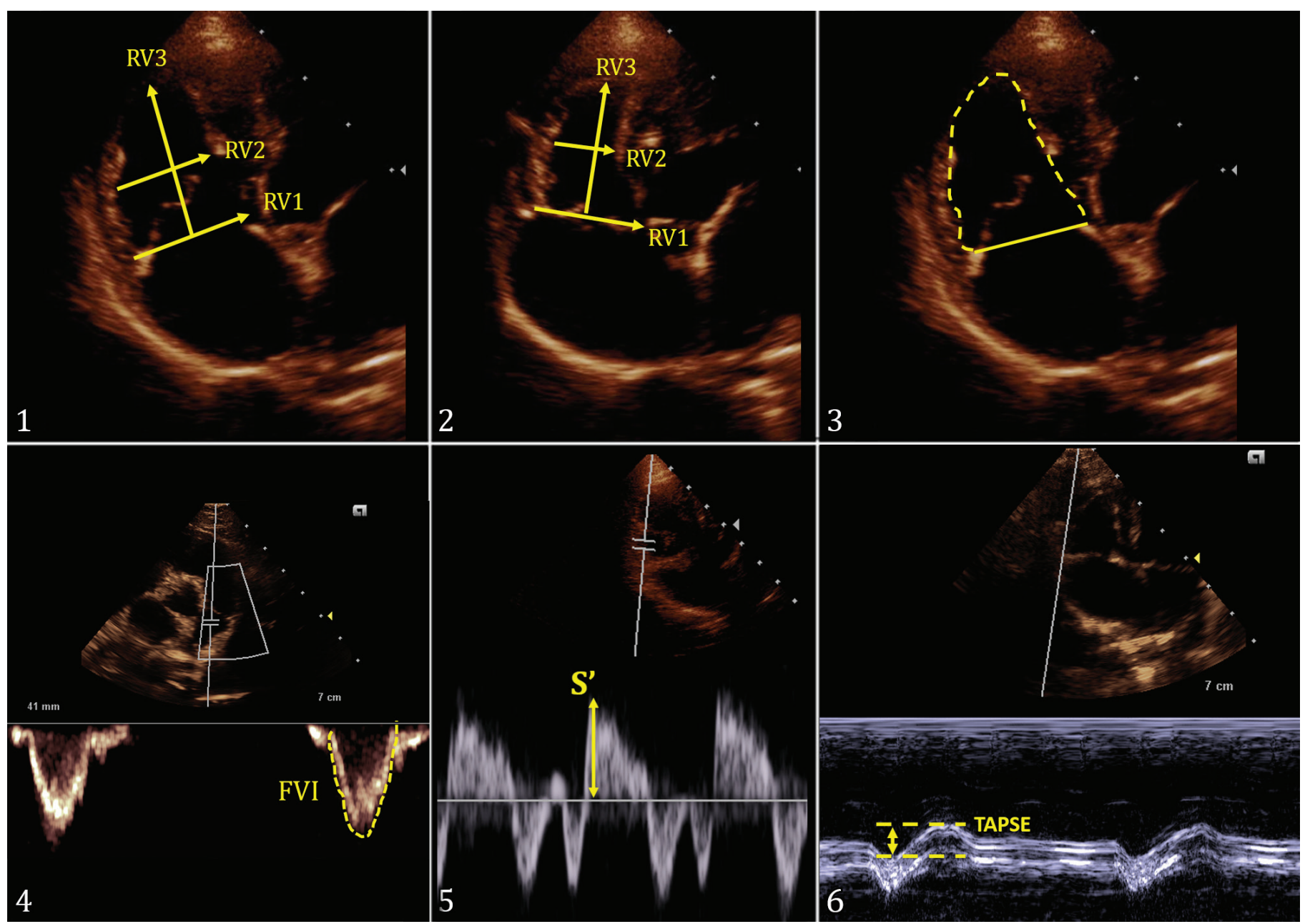

Fig.1-6. Echocardiographic images for right ventricle evaluation. (1) Linear measurements of right ventricle (RV) morphology at diastole in the apical 4-chamber image optimized for the RV; RV1 was measured in the basal third of the RV, RV2 was measured in the middle third of the RV at the level of the left ventricular papillary muscles, and RV3 was measured from the level of the tricuspid annulus to the RV apex. (2) Linear measurements of RV morphology at systole in the apical 4-chamber image optimized for RV, following the same criteria above. (3) Right ventricle end-diastolic area (RVEDA) was obtained by measuring the RV area at diastole (4) Flow velocity integral (FVI) was obtained from the pulsed spectral Doppler contour of the pulmonary flow acquired in the right parasternal view of the pulmonary artery. (5) Pulsed-wave tissue Doppler imaging (TDI) of the tricuspid annulus in apical 4-chamber image optimized for RV, where the positive wave represents the velocity of the systolic wave (S'). (6) Tricuspid annular plane systolic excursion (TAPSE) was obtained in the apical 4-chamber image optimized for RV using M-mode aligned at the tricuspid annulus to measure systolic displacement. 
normality test and Bartlett variance homogeneity test to determine whether the data were parametric or non-parametric. Parametric data were analyzed with ANOVA, considering the severity of PH, while non-parametric data were assessed with the Wilcoxon signed ranks test. The statistical analysis was considered significant at $p<0.05$.

\section{RESULTS}

Sixty-six dogs were included in the study as described above: 60 client-owned dogs fitting the inclusion criteria and 6 institutional animals. Of these, 16 had no $\mathrm{PH}, 24$ dogs were classified as precapillary, and 26 were postcapillary. Among the dogs with $\mathrm{PH}, 28$ had mild cases, 15 were moderate, and seven were severe, based on tricuspid regurgitation velocity. Data on sample age, sex, body weight, and echocardiographic parameters are presented in Table 1 . The dogs without $\mathrm{PH}$ were younger and weighed less than dogs with $\mathrm{PH}$, regardless of severity. The postcapillary group had a larger BSA, indexed LVIDd and LVIDs, LA:Ao ratio, mitral E wave, and mitral E:A ratio compared to the group without $\mathrm{PH}$ and precapillary groups, while the difference was not statistically significant for the group without $\mathrm{PH}$ and precapillary group. No statistically significant difference was seen in left ventricle fractional shortening $\left(\mathrm{FS}_{\mathrm{LV}}\right)$.

The echocardiographic parameters for assessing RV morphology and function are summarized for each group in Table 2. The mean values for RV1d, RV2d, RV3d, RV1s, RV3s, $S^{\prime}$ :Ao ratio, and RVEDA were significantly higher in the $\mathrm{PH}$ group than in the dogs without $\mathrm{PH}$, while FVI was higher in the control group than the PH group. On the other hand, no statistical difference was seen in RV2s, TAPSE:Ao ratio, TAPSE, tricuspid S' or FVI:Ao between dogs with and without $\mathrm{PH}$.

Table 1. Descriptive statistics (either mean standard deviation or median interquartile range and range values) for age, sex, body weight, and left ventricle (LV) echocardiographic indices for the dogs studied, subdivided according to presence of precapillary or postcapillary pulmonary hypertension ( $\mathrm{PH})$

\begin{tabular}{|c|c|c|c|c|}
\hline & \multirow{2}{*}{ No. PH } & \multicolumn{2}{|c|}{ Pulmonary hypertension } & \multirow{2}{*}{$p$ value } \\
\hline & & Precapillary & Postcapillary & \\
\hline $\mathrm{N}$ & 16 & 24 & 26 & - \\
\hline Age (years) & $8.12 \pm 2.92$ & $11.28 \pm 2.91^{\mathrm{a}}$ & $11.71 \pm 2.24^{\mathrm{a}}$ & $<0.001$ \\
\hline $\operatorname{Sex}(F / M)$ & $7 / 9$ & $15 / 11$ & $14 / 12$ & - \\
\hline Body weight (Kg) & $8.00(7.30-11.50)$ & $11.00(10.00-13.00)$ & $12.00(9.25-13.00)$ & 0.079 \\
\hline BSA indexed LVIDd $\left(\mathrm{cm} / \mathrm{m}^{2}\right)$ & $1.45(1.32-1.56)$ & $1.33(1.16-1.64)$ & $1.87(1.63-2.18)^{\mathrm{a}, \mathrm{b}}$ & $<0.001$ \\
\hline BSA indexed LVIDs $\left(\mathrm{cm} / \mathrm{m}^{2}\right)$ & $0.75 \pm 0.17$ & $0.75 \pm 0.25$ & $1.02 \pm 0.16^{\mathrm{ab}}$ & $<0.001$ \\
\hline $\mathrm{FS}_{\mathrm{LV}}(\%)$ & $41.31 \pm 8.05$ & $42.30 \pm 8.68$ & $43.10 \pm 6.76$ & 0.787 \\
\hline LA:Ao & $1.35(1.26-1.46)$ & $1.51(1.27-2.78)$ & $2.39(2.16-2.78)^{\mathrm{a}, \mathrm{b}}$ & $<0.001$ \\
\hline Mitral E (m/s) & $0.65(0.51-0.81)$ & $0.79(0.68-0.92)$ & $1.59(0.95-1.82)^{\mathrm{a}, \mathrm{b}}$ & $<0.001$ \\
\hline Mitral E:A & $1.02(0.79-1.35)$ & $1.06(0.82-1.30)$ & $1.52(1.14-2.06)^{\mathrm{a}, \mathrm{b}}$ & 0.005 \\
\hline
\end{tabular}

$\mathrm{F}=$ Female, $\mathrm{M}=$ male, BSA = body surface area, LVIDd = left ventricle internal diameter in diastole, LVIDs = left ventricle internal diameter in systole, $\mathrm{FS}_{\mathrm{LV}}=$ fractional shortening, LA:Ao = left atrium diameter by aortic diameter ratio, $\mathrm{E}=$ mitral early diastolic wave velocity, $\mathrm{E}: \mathrm{A}=$ mitral early diastolic wave by atrium wave ratio; ${ }^{\mathrm{a}} p<0.05$ compared to no $\mathrm{PH}$ group, ${ }^{\mathrm{b}} p<0.05$ compared to precapillary.

Table 2. Statistical parameters (either mean standard deviation or median interquartile range and range values) for right ventricle (RV) function and echocardiographic morphology indices in dogs with and without pulmonary hypertension (PH)

$\begin{array}{cccr} & \text { No. } \mathrm{PH}(\mathrm{N}=16) & \text { PH } & p \text { value } \\ \text { RV1d } & 0.93(0.83-1.14) & 1.23(1.04-1.06)^{\mathrm{a}} & <0.001 \\ \text { RV2d } & 0.866(0.73-1.12) & 1.02(0.90-1.41)^{\mathrm{a}} & <0.010 \\ \text { RV3d } & 1.67 \pm 0.31 & 2.16 \pm 0.49^{\mathrm{a}} & <0.001 \\ \text { RV1s } & 0.75(0.60-0.80) & 0.91(0.68-1.21)^{\mathrm{a}} & 0.014 \\ \text { RV2s } & 0.57(0.43-0.73) & 0.64(0.52-0.86) & 0.281 \\ \text { RV3s } & 1.33(1.22-1.62) & 1.66(1.47-1.90)^{\mathrm{a}} & 0.002 \\ \text { TAPSE:Ao } & 0.71 \pm 0.23 & 0.85 \pm 0.28 & 0.088 \\ \text { TAPSE mm } & 9.92 \pm 3.39 & 10.81 \pm 3.11 & 0.334 \\ S^{\prime}: \text { Ao } & 0.96(0.78-1.18) & 1.12(0.85-1.44) & 0.135 \\ \text { S }^{\prime} \text { cm/s } & 12.8(10.37-14.30) & 14.30(11.85-16.50) & 0.187 \\ \text { RVEDA m } & 2.3(1.6-3.9) & 3.7(2.6-5.2)^{\mathrm{a}} & 0.031 \\ \text { RVEDA:BSA } & 7.0(4.7-8.5) & 8.4(6.5-10.8)^{\mathrm{a}} & 0.016 \\ \text { FVI:Ao } & 0.80 \pm 0.25 & 0.70 \pm 0.27 & 0.206 \\ \text { FVI } & 10.84 \pm 2.78 & 8.83 \pm 2.77^{\mathrm{a}} & 0.016\end{array}$

RV1 = Basal right ventricle indexed by aortic diameter, RV2 = middle right ventricle indexed by aortic diameter, RV3 = longitudinal right ventricle indexed by aortic diameter $\mathrm{d}=$ diastole, $\mathrm{s}=$ systole, TAPSE = systolic displacement of the tricuspid annulus, TAPSE:Ao = systolic displacement of the tricuspid annulus indexed by aortic diameter, $S^{\prime}=$ maximal annulus tricuspid systolic velocity, $S^{\prime}:$ Ao = maximal annulus tricuspid systolic velocity indexed by aortic diameter, FVIpulm = flow velocity integral, FVIpulm:Ao = flow velocity integral indexed by aortic diameter, RVEDA = right ventricle area in diastole, RVEDA:BSA = right ventricle area in diastole indexed by body surface area; ${ }^{\mathrm{a}} p<0.05$ compared to control group. 
Furthermore, some parameters exhibited a statistically significant difference with regard to severity of $\mathrm{PH}$ compared to the group of dogs without PH: values for RV1d, RV2d, RV1s, and RVEDA were higher in dogs with severe PH than the control group, as seen in Table 3. Meanwhile, values for FVI, FVI:Ao, RV3d, and RV3s were lower in the severe PH group compared with the control or mild $\mathrm{PH}$ groups, and RVEDA:BSA was statistically higher in the severe PH group than in the control, mild, and moderate groups. However, no statistically significant difference was seen for RV2s, TAPSE:Ao ratio, TAPSE or S'.

Table 4 compares the parameters for RV morphology and systolic function in the pre- and postcapillary groups. Statistically significant differences were seen for RV3d, RV1s, S', and S':Ao ratio, with higher mean values in the postcapillary group. Another significant difference was seen in FVI, but in this case the mean values were higher in the

Table 3. Statistical parameters (either mean standard deviation or median interquartile range and range values) for right ventricle (RV) function and echocardiographic morphology indices in dogs with or without pulmonary hypertension (PH), subdivided by severity

\begin{tabular}{|c|c|c|c|c|c|}
\hline & No. PH $(\mathrm{N}=16)$ & Mild $(\mathrm{N}=28)$ & Moderate $(\mathrm{N}=15)$ & Severe $(N=7)$ & $p$ value \\
\hline RV1d & $0.93(0.85-1.14)$ & $1.16(1.09-1.33)^{\mathrm{a}}$ & $1.08(1.02-1.71)^{\mathrm{a}}$ & $1.89(1.11-2.54)^{\mathrm{a}}$ & 0.001 \\
\hline RV2d & $0.87(0.74-1.12)$ & $1.01(0.90-1.26)$ & $1.00(0.87-1.53)$ & $1.68(0.99-2.45)^{\mathrm{a}}$ & 0.012 \\
\hline RV3d & $1.67 \pm 0.31^{\mathrm{b}}$ & $1.94 \pm 0,46$ & $2.13 \pm 0.51^{\mathrm{a}}$ & $2.59 \pm 0.37^{\mathrm{a}, \mathrm{b}}$ & $<0.001$ \\
\hline RV1s & $0.75(0.61-0.80)$ & $0.83(0.64-1.12)$ & $0.91(0.67-1.46)$ & $1.37(0.92-2.29)^{\mathrm{a}}$ & 0.006 \\
\hline RV2s & $0.57(0.43-0.73)$ & $0.60(0.51-0.75)$ & $0.63(0.45-1.24)$ & $1.12(0.67-1.50)$ & 0.062 \\
\hline RV3s & $1.33(1.22-1.62)$ & $1.58(1.32-1.79)$ & $1.67(1.52-2.22)^{\mathrm{a}}$ & $2.16(1.71-2.50)^{\mathrm{a}, \mathrm{b}}$ & 0.004 \\
\hline TAPSE:Ao & $0.71 \pm 0.23$ & $0.88 \pm 0.26$ & $0.86 \pm 0.35$ & $0.68 \pm 0.10$ & 0.133 \\
\hline TAPSE mm & $9.92 \pm 3.92$ & $11.58 \pm 3.32$ & $10.24 \pm 3.08$ & $8.43 \pm 1.76$ & 0.113 \\
\hline$S^{\prime}:$ Ao & $0.96(0.78-1.18)$ & $1.11(0.84-1.54)$ & $1.15(0.85-1.42)$ & $0.99(0.85-1.24)$ & 0.462 \\
\hline $\mathrm{S}^{\prime} \mathrm{cm} / \mathrm{s}$ & $12.80(10.37-14.30)$ & $14.35(11.45-16.32)$ & $15.50(12.50-16.60)$ & $12.60(10.30-14.90)$ & 0.289 \\
\hline RVEDA m ${ }^{2}$ & $2.3(1.6-3.9)$ & $3.4(2.7-4.9)$ & $3.1(2.4-5.1)$ & $6.1(4.7-7.4)^{\mathrm{a}}$ & 0.011 \\
\hline RVEDA:BSA & $7.0(4.7-8.5)$ & $8.0(5.5-10.4)$ & $7.0(6.5-9.4)$ & $15.4(11.7-20.1)^{\mathrm{a}, \mathrm{b}, \mathrm{c}}$ & 0.002 \\
\hline FVI:Ao & $0.80 \pm 0.25$ & $0.75 \pm 0.24$ & $0.71 \pm 0.32$ & $0.41 \pm 0.13^{\mathrm{a}, \mathrm{b}}$ & 0.035 \\
\hline FVI cm & $10.84 \pm 2.78$ & $9.70 \pm 2.77$ & $8.37 \pm 1.66$ & $5.30 \pm 2.14^{\mathrm{a}, \mathrm{b}}$ & $<0.001$ \\
\hline
\end{tabular}

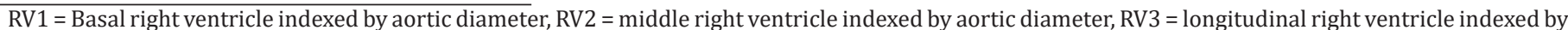

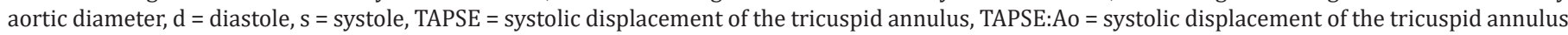

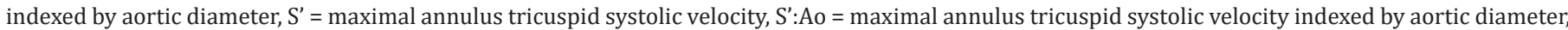

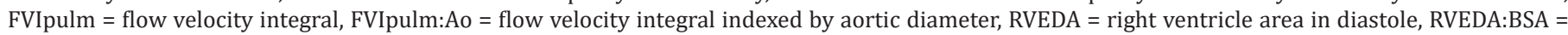

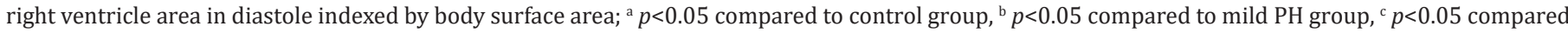
to moderate $\mathrm{PH}$ group.

Table 4. Statistical parameters (either mean standard deviation or median interquartile range and range values) for right ventricle (RV) function and echocardiographic morphology indices for the studied dogs, subdivided according to presence of precapillary or postcapillary pulmonary hypertension (PH)

\begin{tabular}{cccc}
\hline & Precapillary PH & Postcapillary PH & $p$ value \\
\hline RV1d & $1.13 \pm 0.24$ & $1.29 \pm 0.46$ & 0.08 \\
RV2d & $0.99 \pm 0.28$ & $1.01 \pm 0.37$ & 0.2 \\
RV3d & $1.82 \pm 0.48$ & $2.20 \pm 0,41^{\mathrm{a}}$ & 0.0014 \\
RV1s & $0.78 \pm 0.45$ & $1.02 \pm 0.23^{\mathrm{a}}$ & 0.03 \\
RV2s & $0.63 \pm 0.18$ & $0.66 \pm 0.36$ & 0.2 \\
RV3s & $1.60 \pm 0.38$ & $1.68 \pm 0.41$ & 0.07 \\
TAPSE:Ao & $0.76 \pm 0.24$ & $0.91 \pm 0.30$ & 0.24 \\
TAPSE mm & $11.25 \pm 3.42$ & $10.70 \pm 3.10$ & 0.55 \\
S':Ao & $0.96 \pm 0.27$ & $1.32 \pm 0.35^{\mathrm{a}}$ & 0.0076 \\
S' cm/s & $13.6 \pm 2.95$ & $15.3 \pm 3.79$ & 0.046 \\
RVEDA m ${ }^{2}$ & $3.63 \pm 2.11$ & $3.87 \pm 2.16$ & 0.98 \\
RVEDA:BSA & $8.65 \pm 3.68$ & $8.33 \pm 3.82$ & 0.9 \\
FVI:Ao & $0.75 \pm 0.20$ & $0.56 \pm 0.34$ & 0.6 \\
FVI cm & $9.90 \pm 1.44$ & $8.00 \pm 2.11^{\mathrm{a}}$ & 0.00027
\end{tabular}

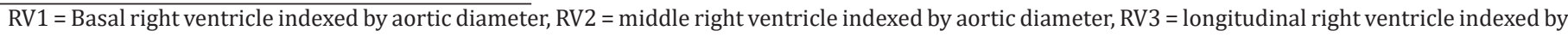

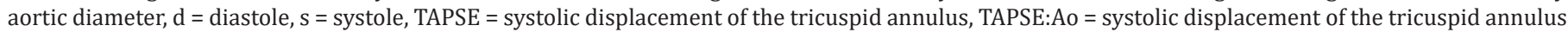

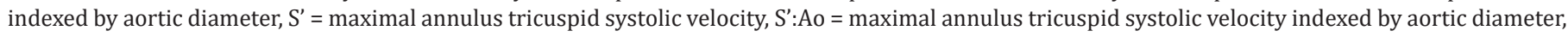

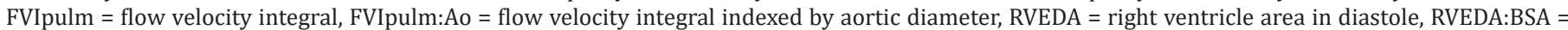
right ventricle area in diastole indexed by body surface area; ${ }^{a} p<0.05$ compared to precapillary group. 
precapillary group. No significant difference was seen in the other evaluated RV parameters.

As a reference range for RV morphology, Gentile-Solomon \& Abbott (2016) proposed values for normal dogs; we applied only the RV1 and RV3 measures. In our analysis, RV1d was increased in postcapillary (8/22, with 4 dogs upper borderline) and precapillary ( $8 / 23$, with 5 additional dogs upper borderline) PH dogs, distributed across all severities of PH. For RV1 in systole, few values were elevated in postcapillary cases (4/22, with 6 dogs upper borderline) and precapillary cases (1/23, with 7 dogs upper borderline). RV3d was also verified and severe and moderate postcapillary $\mathrm{PH}$ dogs were at the upper end of the reference range, while dogs with severe and moderate precapillary $\mathrm{PH}$ had values within the reference range. Additionally, two dogs that were diagnosed with right heart failure and ascites due to severe precapillary PH from chronic bronchitis did not show left cardiac remodeling or signs of left heart failure. On the other hand, nearly all the dogs with severe postcapillary $\mathrm{PH}$ exhibited at least one sign of right heart failure, such as ascites, pleural effusion, jugular pulse, or venous congestion of the liver. For other measurements of RV morphology, few values were above the reference range.

As for TDI, all the dogs in our study presented values within the reference range (mean $\mathrm{S}^{\prime}: 12.5 \pm 3.2 \mathrm{~cm} / \mathrm{s}$, reference range: $7.7-18.5 \mathrm{~cm} / \mathrm{s}$ ) (Chetboul et al. 2005). The coefficient of variation (CV) was calculated for S' and $\mathrm{S}^{\prime}$ :Ao. The CV was high in the control group (34.9\%) as well as the $\mathrm{PH}$ group $(28.8 \%)$. We divided the $S^{\prime}$ value by the aortic diameter ( $\left.\mathrm{S}^{\prime}: \mathrm{Ao}\right)$ obtained from the transversal view of the aortic plane. The CV for this index remained high in the control group (32.8\%) and the PH groups (34.1\%); although the CV was high for $\mathrm{S}^{\prime}$ :Ao in the precapillary $(32.8 \%)$ and postcapillary groups (28\%), the means were statistically different.

\section{DISCUSSION}

To assess the right ventricle, Rudski et al. (2010) proposed linear measurements such as the minor RV basal (RV1), mid-cavity (RV2), and longitudinal RV (RV3) dimensions to help assess ventricular dilatation and monitor morphology. These parameters can also be used in animals, and in our study successfully differentiated dogs with PH dogs from those without this condition (with the exception of RV2). Furthermore, RV1d and RV3 notably distinguished severe PH from cases where PH was not present; although a statistically significant difference was not seen for RV2s, it tended to differentiate dogs with and without $\mathrm{PH}$ with a low $p$ value, which could be further investigated in additional studies. It is important to highlight that the RV remodeling in $\mathrm{PH}$ can be either adaptive (concentric hypertrophy preserving the systolic and diastolic function of the RV) or non-adaptive (characterized by eccentric hypertrophy with impairment of systolic and diastolic function of the RV) (Vonk-Noordegraaf et al. 2013). Because of the different responses, we applied the values proposed by Gentile-Solomon \& Abbott (2016) as a reference range to individually verify RV morphology in normal dogs. In our analysis, RV measurements in diastole from the tricuspid annulus that refer to RV1d were able to identify an increase in RV for more than a third of dogs with $\mathrm{PH}$, in both the postcapillary (8/22, with 4 dogs upper borderline) and precapillary (8/23, with 5 additional dogs upper borderline) groups. Thus, some of these patients had marked RV remodeling, while it was slight or absent in others. It should be noted that the dogs with RV enlargement were distributed across all severities of $\mathrm{PH}$, not just the most severe stages, and this distribution shows that gradual process of remodeling is variable in dogs, in both precapillary and postcapillary $\mathrm{PH}$. One possible explanation for the lack of a significant difference in RV1d between the pre- and postcapillary PH groups is that there was a similar number of dogs with increased RV in each group; both groups exceeded the reference values and the control group showed values within the reference range.

Few values for RV1 in systole were elevated in postcapillary cases (4/22, with 6 dogs upper borderline) and precapillary cases (1/23, with 7 dogs upper borderline). For other measurements of RV morphology, very few values exceeded the reference range; this could be justified by the adaptative process of the RV in $\mathrm{PH}$.

On the other hand, RV3d alone was able to distinguish RV morphology in the pre- and postcapillary groups. Mean values for the postcapillary group were higher than for the precapillary group, because values for severe and moderate postcapillary PH dogs were at the upper end of the reference range, while no increase was seen in precapillary cases. This could be explained by congestion and increased preload involved during the process of cardiac failure from MMVD. In this situation, low cardiac output as a consequence of mitral valve insufficiency promotes a decrease in systemic blood pressure that results in activation of the RAAS by cardiac baroreceptors. This activation produces an increase in afterload and preload, which in turn promotes pulmonary venous congestion. Because of the effect of the transpulmonary gradient, pulmonary venous congestion results in pulmonary arterial vasoconstriction and increased RV afterload, which is rarely seen in chronic respiratory disease (Galiè et al. 2009). Precapillary $\mathrm{PH}$ is caused by pulmonary diseases or hypoxia (Reinero et al. 2020). In such cases, the pulmonary arterial bed responds differently than the rest of the body vasculature, promoting vasoconstriction which increases pulmonary vascular resistance and consequently causes RV pressure overload (Kellihan et al. 2015). Only two dogs in our sample had right cardiac failure with ascites due to severe precapillary PH from chronic bronchitis, and neither presented left heart remodeling or signs of left cardiac failure. Meanwhile, nearly all the severe postcapillary PH dogs exhibited at least one sign of right cardiac failure such as ascites, pleural effusion, jugular pulse, or venous liver congestion. We believe that RAAS activation in postcapillary $\mathrm{PH}$ promoting congestion and increased preload facilitate the process of eccentric right heart remodeling (non-adaptative response). This occurs in a similar but slower manner in precapillary $\mathrm{PH}$, since activating the RAAS requires low cardiac output; this is present in MMVD, but in precapillary PH it only occurs when systolic RV function is impaired (Galiè et al. 2009).

The parameters for RV morphology have been seen to be useful in clinical practice to accompany patient evolution in terms of PH and determine how quickly RV remodeling appears compared to baseline and life-long measures to suggest a prognosis. They are also important since postcapillary $\mathrm{PH}$ is a consequence of left heart disease, MMVD is very frequent in dogs, and precapillary $\mathrm{PH}$ is caused by pulmonary diseases or hypoxia which are also frequently seen in clinical practice (Kellihan \& Stepien 2010, Kellihan et al. 2015). 
TAPSE has been suggested as an assessment of RV function in dogs; this parameter measures the longitudinal displacement of the lateral tricuspid annulus during systole, and increases with body size (Visser et al. 2015). In the present study, no difference was seen in TAPSE value, possibly because the reference range for TAPSE is broad and increases with weight (Pariaut et al. 2012, Gentile-Solomon \& Abbott 2016, Caivano et al. 2018). For this reason, indexed parameters could be a good solution to reduce interference resulting from body weight (Gentile-Solomon \& Abbott 2016), but TAPSE:Ao was not seen to be effective, and other indexes should be tested. Vezzosi et al. (2018) examined values of TAPSE normalized for body weight in $\mathrm{PH}$ and control groups of dogs and found no statistically significant difference; furthermore, these values were lower in dogs with precapillary PH than in postcapillary cases. On the other hand, Pariaut et al. (2012) found that TAPSE was a marker for decreased RV systolic function when signs of right-sided congestive heart failure were present. Moreover, dogs with mild to moderate $\mathrm{PH}$ did not differ from the dogs in control group, and although TAPSE was at the lower end it was still within the reference range. The literature on RV systolic function in dogs with PH presents discrepancies. Other studies found that these values do not change with PH severity in dogs with MMVD (Tidholm et al. 2015, Poser et al. 2017). The gradual process of compensatory mechanisms presented by patients with MMVD are well known; these mechanisms are initially activated and lead to the increase in preload, with the myocardium still preserved. We can consequently presume that as the Frank-Starling mechanism explains the preservation of left ventricle systolic function, it could also preserve right ventricle function, which may indicate why TAPSE did not change in our study. Furthermore, in precapillary $\mathrm{PH}$ it must be considered that when there is pulmonary vascular resistance, the RV is subjected to pressure overload and increases contractility, which leads to hypertrophy and subsequent dilation before right heart failure (Galiè et al. 2009, Vonk-Noordegraaf et al. 2013).

TDI is a validated tool for assessing systolic and diastolic myocardial function in dogs (Madron 2015). It is limited by the insonation angle, and as a result it is easier to obtain RV measurements from the apical four chamber axis view to obtain the best alignment. Notably, although the distribution of myocardium fibers in the ventricles has been widely studied in humans, studies on dogs have mostly focused on the LV. Different LV values for dogs can be found in the literature, depending on whether the TDI is obtained from subendocardium or subepicardium fibers (Madron 2015). We did not address this issue in our study; instead, we did a global TDI from the tricuspid annulus and utilized reference values obtained from a study that included several breeds. According to these data, all the dogs in our study had values within the reference range (Chetboul et al. 2005). Another important factor is that TDI values vary between breeds (Chetboul et al. 2005), and while our study group included a variety of different breeds, few dogs comprised subgroups of the same breed. Furthermore, another important factor is that the coefficient of variation (CV) calculated for S' and S':Ao was high in all the tested groups (control, precapillary, and postcapillary $\mathrm{PH}$ ), which shows the range of values despite the $S$ 'values being within the reference range. The explanations presented above that speculate about the lack of change in
TAPSE among the dogs evaluated in this study could also justify the absence of changes in the $S^{\prime}$ and $S^{\prime}$ :Ao values. This is particularly relevant when noting that the postcapillary $\mathrm{PH}$ group has a statistically greater mean than the precapillary PH group, since the Frank-Starling mechanism could be able to increase myocardial responsiveness before causing right cardiac heart failure. This mechanism could maintain normal $S^{\prime}$ values or even increase them during this phase.

RVEDA is a two-dimensional measure of RV size which estimates RV area, and is indexed to body surface area; this value can increase with the severity of PH (Poser et al. 2017). The findings by Vezzosi et al. (2018) for RVEDA were similar to those from our study, in which the PH group also presented higher values than the control group. These authors also found that the control and mild PH groups could be distinguished from dogs with moderate and severe PH, and RVEDA could identify dogs with right congestive heart failure (Vezzosi et al. 2018). This was similar to our study because the severe $\mathrm{PH}$ group also could be distinguished from the control group, and presented at least one sign of right heart failure. Poser et al. (2017) found no difference in RV size at different stages of PH using a linear measure obtained in M-mode, while Pariaut et al. (2012) noted an increase in RV size even in mild $\mathrm{PH}$ through subjective evaluation. The two methodologies in these studies to infer about RV size are more error-prone, since other research has shown that different techniques are more effective and standardized for assessing the RV in humans (Rudski et al. 2010, Ling et al. 2012). RVEDA could be a potential tool for use in clinical routine to identify RV remodeling, but additional study is still required due to the lack of consensus.

$\mathrm{FVI}_{\text {pulm }}$ (flow velocity integral or time-velocity integral) is a linear variable used to estimate the volume ejected by the RV in systole (Petrus et al. 2010). This measure is obtained from the area under the Doppler flow velocity curve $(\mathrm{cm} / \mathrm{s})$ $\mathrm{x}$ ejection time (s) and exhibited in centimeters, which indicates distance (Gardin 2018). The FVI ${ }_{\text {pulm }}$ value can be influenced by pulmonary vascular resistance, which can be estimated by the ratio of tricuspid regurgitation and the FVI $_{\text {pulm }}$ (Jone \& Ivy 2014). Moreover, it has been identified as an indicator of the presence of RV fibrosis in human patients with pulmonary arterial hypertension, whose $\mathrm{FVI}_{\text {pulm }}$ values were low (Soma et al. 2013). As already shown, patients in our study also had low mean FVI $_{\text {pulm }}$ (postcapillary PH) and FVI:Ao (postcapillary and severe PH) values, possibly suggesting RV systolic function impairment. This may indicate that FVI ${ }_{\text {pulm }}$ and FVI:Ao decrease in the presence of PH in dogs and especially when there is progression of $\mathrm{PH}$, but studies on these parameters to confirm this hypothesis are scarce in dogs. Since RV ejection volume depends on contraction of the cardiac muscle fibers and the resistance imposed by the pulmonary artery, RV wall contractility in $\mathrm{PH}$ is believed to be insufficient to overcome the increased afterload imposed by the pulmonary vasculature resistance, as explained in nonadaptative RV remodeling (Vonk-Noordegraaf et al. 2013).

Guidelines on PH in dogs have recently been published to establish a classification based not only on tricuspid regurgitation but also qualitative RV morphologic criteria, RV systolic disfunction, pulmonary artery alterations, and caudal vena cava alteration to predict the probability of $\mathrm{PH}$. However, these guidelines were published after this study 
had been designed, and not all of the new recommendations for PH classification could be included (Reinero et al. 2020). Nevertheless, we noted in this sample that PH seems to be more severe in patients with right cardiac remodeling regardless of TR velocity, as well as some patients with high TR velocities did not show other signs of PH.

\section{CONCLUSIONS}

Several echocardiographic variables proposed for the study of the right ventricle (RV) morphology and systolic function showed remodeling and systolic dysfunction of the $\mathrm{RV}$ in the presence of pulmonary hipertension (PH). In this study, longitudinal right ventricle indexed by aortic diameter - diastolic (RV3d), basal right ventricle indexed by aortic diameter - systolic (RV1s), maximal annulus tricuspid systolic velocity indexed by aortic diameter ( $\mathrm{S}^{\prime}:$ Ao), maximal annulus tricuspid systolic velocity $\left(\mathrm{S}^{\prime}\right)$, and flow velocity integral (FVI) were able to distinguish cases of pre- and postcapillary $\mathrm{PH}$. Remodeling of the RV was also observed in dogs with PH, which can be influenced by the pre- or postcapillary origin of $\mathrm{PH}$, with dilation in dogs with postcapillary $\mathrm{PH}$ as well as severe PH. The results for RV systolic function exhibited similar behavior, with FVI and FVI:Ao indicating reduced RV ejection function in dogs with postcapillary $\mathrm{PH}$ and also in severe $\mathrm{PH}$.

We consequently believe that these parameters can be utilized in routine echocardiographic diagnosis as classification criteria, expanding on this method to help clinicians predict right heart failure, determine the most appropriate treatment, and also estimate the patient's prognosis, since remodeling and dysfunction of the RV can culminate in right heart failure.

Acknowledgments.- This manuscript was reviewed by a professional science editor and a native English-speaking copy editor to improve readability. The authors thank the "Coordenação de Aperfeiçoamento de Pessoal de Nível Superior" (CAPES) for financial support, and the Cardiology Service at the Unesp Veterinary Hospital for logistical assistance to conduct the study.

Conflict of interest statement.- The authors declare that they have no conflict of interest.

\section{REFERENCES}

Caivano D., Dickson D., Pariaut R., Stillman M. \& Rishniw M. 2018. Tricuspid annular plane systolic excursion-to-aortic ratio provides a bodyweightindependent measure of right ventricular systolic function in dogs. J. Vet. Cardiol. 20(2):79-91. <https://dx.doi.org/10.1016/j.jvc.2018.01.005> <PMid:29503235>

Chetboul V., Bussadori C. \& Madron É. 2016. Clinical Echocardiography of the Dog and Cat. Elsevier, Masson, p.47-84.

Chetboul V., Sampedrano C.C., Gouni V., Concordet D., Lamour T., Ginesta J., Nicolle A.P., Pouchelon J.L. \& Lefebvre H.P. 2005. Quantitative assessment of regional right ventricular myocardial velocities in awake dogs by Doppler tissue imaging: repeatability, reproducibility, effect of body weight and breed, and comparison with left ventricular myocardial velocities. J. Vet. Intern. Med. 19(6):837-844. <https://dx.doi.org/10.1892/08916640(2005)19[837:qaorrv]2.0.co;2><PMid:16355678>

Chun R., Garrett L.D. \& Vail D.M. 2007. Cancer chemotherapy, p.163-192. In: Vail D.M. (Ed.), Withrow and MacEwen's Small Animal Clinical Oncology. 4th ed. W.B. Saunders, St. Louis.

Fields A., Roberts J. \& Forfia P. 2011. Serial TAPSE at 1 year, not baseline TAPSE, predicts survival differences in patients with an incident diagnosis of pulmonary arterial hypertension. Chest 140(4_MeetingAbstracts):749A. <https://dx.doi.org/10.1378/chest.1116846>
Freed B.H., Collins J.D., François C.J., Barker A.J., Cuttica M.J., Chesler N.C.,, Markl M. \& Shah S.J. 2016. MR and CT Imaging for the Evaluation of Pulmonary Hypertension. JACC Cardiovasc. Imag. 9(6):715-732. <https://dx.doi. org/10.1016/j.jcmg.2015.12.015><PMid:27282439>

Galiè N., Hoeper M.M., Humbert M., Torbicki A., Vachiery J.L., Barbera J.A., Beghetti M., Corris P., Gaine S., Gibbs J.S., Gomez-Sanchez M.A., Jondeau G., Klepetko W., Opitz C., Peacock A., Rubin L., Zellweger M. \& Simonneau G. 2009. ESC Committee for Practice Guidelines (CPG). Guidelines for the diagnosis and treatment of pulmonary hypertension: the Task Force for the Diagnosis and Treatment of Pulmonary Hypertension of the European Society of Cardiology (ESC) and the European Respiratory Society (ERS), endorsed by the International Society of Heart and Lung Transplantation (ISHLT). Eur. Heart J. 30(20):2493-537. <https://dx.doi.org/10.1093/ eurheartj/ehp297> <PMid:19713419>

Gardin J.M. 2018. Pulsed Doppler echocardiography: an historical perspective. J. Am. Soc. Echocardiogr. 31(12):1330-1343. <https://dx.doi.org/10.1016/j. echo.2018.09.013><PMid:30522606>

Gentile-Solomon J.M. \& Abbott J.A. 2016. Conventional echocardiographic assessment of the canine right heart: reference intervals and repeatability. J. Vet. Cardiol. 18(3):234-247.<https://dx.doi.org/10.1016/j.jvc.2016.05.002> <PMid:27453517>

Greyson C.R. 2010. The right ventricle and pulmonary circulation: basic concepts. Revta Esp. Cardiol. 63(1):81-95. < https://dx.doi.org/10.1016/ S1885-5857(10)70012-8><PMid:20089229>

Grünig E., Biskupek J., D’Andrea A., Ehlken N., Egenlauf B., Weidenhammer J., Marra A.M., Cittadini A., Fischer C. \& Bossone E. 2015. Reference ranges for and determinants of right ventricular area in healthy adults by twodimensional echocardiography. Respiration 89(4):284-293. <https:// dx.doi.org/10.1159/000371472><PMid:25765954>

Jone P.N. \& Ivy D.D. 2014. Echocardiography in pediatric pulmonary hypertension. Front. Pediatr. 2:124. <https://dx.doi.org/10.3389/fped.2014.00124> <PMid:25429362>

Kellihan H.B. \& Stepien R.L. 2010. Pulmonary hypertension in dogs: diagnosis and therapy. Vet. Clin. N. Am., Small Anim. Pract. 40(4):623-641. <https:// dx.doi.org/10.1016/j.cvsm.2010.03.011><PMid:20610015>

Kellihan H.B. \& Stepien R.L. 2012. Pulmonary hypertension in canine degenerative mitral valve disease. J. Vet. Cardiol.14(1):149-164. <https:// dx.doi.org/10.1016/j.jvc.2012.01.001><PMid:22364721>

Kellihan H.B., Waller K.R., Pinkos A., Steinberg H. \& Bates M.L. 2015. Acute resolution of pulmonary alveolar infiltrates in 10 dogs with pulmonary hypertension treated with sildenafil citrate: 2005-2014. J. Vet. Cardiol. 17(3):182-191. <https://dx.doi.org/10.1016/j.jvc.2015.04.002> <PMid:26293206>

Lang R.M., Badano L.P., Mor-Avi V., Afilalo J., Armstrong A., Ernande L., Flachskampf F.A., Foster E., Goldstein S.A., Kuznetsova T., Lancellotti P., Muraru D., Picard M.H., Rietzschel E.R., Rudski L., Spencer K.T., Tsang W. \& Voigt J.U. 2015. Recommendations for cardiac chamber quantification by echocardiography in adults: an update from the American Society of Echocardiography and the European Association of Cardiovascular Imaging. Eur. Heart J. Cardiovasc. Imag. 16(3):233-270. <https://dx.doi. org/10.1093/ehjci/jev014><PMid:25712077>

Ling L.F., Obuchowski N.A., Rodriguez L., Popovic Z., Kwon D. \& Marwick T.H. 2012. Echocardiographic assessment of right ventricular size and systolic function: a quality control exercise. J. Am. Soc. Echocardiogr. 25(7):709713. <https://dx.doi.org/10.1016/j.echo.2012.03.018><PMid:22542275>

Madron E. 2015. Evaluation of the right ventricle global systolic function, p.151-156. In: Madron E., Chetboul V. \& Bussadori C. (Eds), Clinical Echocardiography of the Dog and Cat. Elsevier, St Louis.

Paige C.F., Abbott J.A. \& Pyle R.L. 2007. Systolic anterior motion of the mitral valve associated with right ventricular systolic hypertension in 9 dogs. J. Vet. Cardiol. 9(1):9-14. <https://dx.doi.org/10.1016/j.jvc.2006.08.003> <PMid:17689464> 
Pariaut R., Saelinger C., Strickland K.N., Beaufrère H., Reynolds C.A. \& Vila J. 2012. Tricuspid annular plane systolic excursion (TAPSE) in dogs: reference values and impact of pulmonary hypertension. J. Vet. Intern. Med. 26(5):1148-1154. <https://dx.doi.org/10.1111/j.1939-1676.2012.00981.x> $<$ PMid:22860631>

Petrus L.C., Oliveira V.M.C., Pereira G.G. \& Larsson M.H.M.A. 2010. Avaliação dos fluxos das valvas aórtica e pulmonar com ecocardiografia Doppler pulsátil em cães clinicamente sadios. Pesq. Vet. Bras. 30(7):586-592. <https://dx.doi.org/10.1590/S0100-736X2010000700013>

Poser H., Berlanda M., Monacolli M., Contiero B., Coltro A. \& Guglielmini C. 2017. Tricuspid annular plane systolic excursion in dogs with myxomatous mitral valve disease with and without pulmonary hypertension. J. Vet. Cardiol. 19(3):228-239. <https://dx.doi.org/10.1016/j.jvc.2017.03.007> $<$ PMid:28579307>

Reinero C., Visser L., Kellihan H., Masseau I., Rozanski E., Clercx C., Williams K., AbbottJ., Borgarelli M. \& Scansen B. 2020. ACVIM consensus statement guidelines for the diagnosis, classification, treatment, and monitoring of pulmonary hypertension in dogs. J. Vet. Intern. Med. 34(2):549-573. <https://dx.doi.org/10.1111/jvim.15725>

Rudski L.G., Lai W.W., Afilalo J., Hua L., Handschumacher M.D., Chandrasekaran K., Solomon S.D., Louie E.K. \& Schiller N.B. 2010. Guidelines for the echocardiographic assessment of the right heart in adults: a report from the American Society of Echocardiography endorsed by the European Association of Echocardiography, a registered branch of the European Society of Cardiology, and the Canadian Society of Echocardiography. J. Am. Soc. Echocardiogr. 23(7):685-713. <https://dx.doi.org/10.1016/j. echo.2010.05.010 > <PMid:20620859>

Soma S.K.R., Raghuveer D., Prabhakar S., Biederman R. \& Raina A. 2013. Right ventricular outflow velocity time integral is the strongest echo-doppler predictor of right ventricular fibrosis in patients with pulmonary arterial hypertension. J. Heart Lung Transplant. 32(4Supl.):S106-S107. <https:// dx.doi.org/10.1016/j.healun.2013.01.1034>
Szabó G., Soós P., Bährle S., Radovits T., Weigang E., Kékesi V., Merkely B. \& Hagl S. 2006. Adaptation of the right ventricle to an increased afterload in the chronically volume overloaded heart. Ann. Thorac. Surg. 82(3):989-995. <https://dx.doi.org/10.1016/j.athoracsur.2006.04.036><PMid:16928521>

Tidholm A., Höglund K., Häggström J. \& Ljungvall I. 2015. Diagnostic value of selected echocardiographic variables to identify pulmonary hypertension in dogs with myxomatous mitral valve disease. J. Vet. Intern. Med. 29(6):15101517. <https://dx.doi.org/10.1111/jvim.13609><PMid:26365438>

Vezzosi T., Domenech O., Costa G., Marchesotti F., Venco L., Zini E., Del Palacio M.J.F. \& Tognetti R. 2018. Echocardiographic evaluation of the right ventricular dimension and systolic function in dogs with pulmonary hypertension. J. Vet. Intern. Med. 32(5):1541-1548. <https://dx.doi. org/10.1111/jvim.15253><PMid:30216561>

Visser L.C., Im M.K., Johnson L.R. \& Stern J.A. 2015. Diagnostic value of right pulmonary artery distensibility index in dogs with pulmonary hypertension: comparison with doppler echocardiographic estimates of pulmonary arterial pressure. J. Vet. Intern. Med. 30(2):543-552. <https:// dx.doi.org/10.1111/jvim.13911> <PMid:26893108>

Visser L.C., Scansen B.A., Schober K.E. \& Bonagura J.D. 2014. Echocardiographic assessment of right ventricular systolic function in conscious healthy dogs: repeatability and reference intervals. J. Vet. Cardiol. 17(2):83-96.<https:// dx.doi.org/10.1016/j.jvc.2014.10.003><PMid:25547662>

Vonk Noordegraaf A., Westerhof B.E. \& Westerhof N. 2017. The relationship between the right ventricle and its load in pulmonary hypertension. J. Am. Coll. Cardiol. 69(2):236-243. <https://dx.doi.org/10.1016/j. jacc.2016.10.047><PMid:28081831>

Vonk-Noordegraaf A., Haddad F., Chin K.M., Forfia P.R., Kawut S.M., Lumens J., Naeije R., Newman J., Oudiz R.J., Provencher S., Torbicki A., Voelkel N.F. \& Hassoun P.M. 2013. Right heart adaptation to pulmonary arterial hypertension: physiology and pathobiology. J. Am. Coll. Cardiol. 62(Supl.25):D22-D33. <https://dx.doi.org/10.1016/j.jacc.2013.10.027><PMid:24355638> 